\title{
Criatividade na Atuação: estratégias para a separação da identidade real do artista de sua construção na Nigéria
}

\author{
Osakue S. Omoera \\ Ph.D \\ Departamento de Teatro e Artes Midiáticas, Faculdade de Artes, Universidade de AmbroseAlli, Ekpoma \\ Email: omoera@yahoo.com, osakueomoera@gmail.com \\ Emmanuel Ozoemenam \\ Departmento de Teatro, Faculdade de Artes, Universidade de Ibadan, Ibadan \\ Email: gpsunny2001@yahoo.com
}

Resumo

Este artigo centra-se na arte da atuação na Nigéria. Sua problemática é informada pelo comportamento de alguns intérpretes que tendem a viver sua "vida nos palcos/ nas telas" em suas vidas cotidianas, o que muitas vezes resulta em conflito entre sua personalidade real e suas construções. O estudo adota métodos histórico-analíticos de entrevista e observação para examinar esse equívoco, e como esses conceitos falsos geram uma falta de apreciação, por parte da sociedade, das artes do teatro como uma disciplina. Além disso, argumenta-se que, embora eles tenham sido vistos ao longo do tempo como artistas, eles devem treinar para separar cuidadosamente o que constroem nos palcos de suas vidas cotidianas. $\mathrm{O}$ artigo sugere, entre outras coisas, a autodescoberta, o equilíbrio psicológico/ consciência e o distanciamento psicológico como soluções para o desafio. Conclui-se que os principais requisitos dos atores/atrizes são o senso comum, potências aguçadas de observação e percepção, tolerância e compreensão do comportamento humano e um conhecimento geral sólido da sociedade para que, assim, aprofunde o entendendimento das artes teatrais como uma profissão na sociedade nigeriana contemporânea.

Palavras-chave

Criatividade em atuação. Drama. Palco/tela. Intérprete/Ator/Atriz, Identidade Real. Construção. Sociedade Nigeriana Contemporânea.
Abstract

This article centres on the art of acting in Nigeria. Its problematic is informed by the behaviour of some actors/actresses/performers who tend to live their 'stage life' or 'screen life' in their normal everyday living. The study adopts the historical-analytic, interview and observation methods to examine this misconception and how they colour the society's appreciation of theatre arts as a discipline. It further argues that although actors/actresses have been seen as entertainers, they should train on how to neatly separate what they construct on stage from their daily living. The paper suggests, among other things, self-discovery and psychological distancing as panaceas to the challenge. It concludes that the actors'/actresses' prime requisites are common sense, acute powers of observation and perception, tolerance and understanding of human behaviour and a general knowledge of society, in order to deepen the professional understanding of theatre arts as a profession in the contemporary Nigerian society.

Keywords

Creativity in acting. Drama. Stage/Screen. Performer/Actor/Actress. Real identity. Construct. Contemporary Nigerian society. 


\section{Introdução}

O drama começa com uma construção disciplinada e um acordo ordenado por palavras e ações, e essas ações são realizadas como performance pelo ator / atriz / intérprete tanto nos palcos como nas telas. O drama é uma ação, e uma ação dramática resoluta é atuação, e a atuação não pode ser realizada sem atores / atrizes / personagens. Consequentemente, há pontos vitais a serem observados sobre $o$ ator / atriz e sua atuação em relação à sua personalidade e à sua pessoa ator/ atriz. A fim de melhorar a apreciação, na sociedade, do ator / atriz, do seu gênio criativo e do seu trabalho, que é fundamental para o prazer de viver da humanidade, uma busca pela identidade real do artista e seu nexo de construção se faz pertinente. A problemática deste estudo é informada pelo comportamento de alguns atores / artistas nigerianos que tendem a viver suas "vidas nos palcos" ou "vidas nas telas" em sua vida cotidiana normal, o que resulta em conflito entre suas personalidades reais e personalidades construídas. Este artigo adota métodos histórico-analíticos e artísticos para examinar o equívoco de alguns intérpretes / atores / atrizes sobre sua criatividade nos palcos ou nas telas, sua vida cotidiana normal e como esses equívocos geram uma falta de apreciação, por parte da sociedade, das artes do teatro como uma disciplina.

Argumenta-se que, embora os atores / atrizes tenham sido vistos ao longo dos tempos como artistas, eles deveriam treinar-se para separar cuidadosamente o que eles construíram nos palcos / telas de sua vida cotidiana. Para este fim, este artigo sugere, entre outras coisas, a autodescoberta, o equilíbrio/ consciência psicológica e o distanciamento psicoló- gico como soluções para o desafio. Conclui-se que os principais requisitos do ator ou da atriz são o senso comum, potências aguçadas de observação e percepção, tolerância e compreensão do comportamento humano e um conhecimento geral sensato sobre a sociedade, onde os artistas representam seres humanos e outros fenômenos com fidelidade. $\mathrm{O}$ artigo também sustenta que tal esforço deliberado ajudará a aprofundar a tendência profissional que as artes de teatro como uma profissão necessitam desesperadamente na Nigéria contemporânea.

Ao longo dos tempos, não faltam materiais críticos sobre como filósofos, estudiosos e críticos viam a personalidade do ator / atriz. $\mathrm{Na}$ era clássica, Platão foi o primeiro a escrever sobre a pessoa do ator em seu trabalho, A República (cerca de 373 a.c). É de conhecimento comum que Platão atacou atores e poetas e os excluiu da sua república ideal argumentando que seus atos estavam no domínio da ilusão, o que é três vezes retirado do original. Segundo ele, os atores deturpavam os deuses e os heróis. Deus é perfeitamente bom e, portanto, é imutável e incapaz de enganar, mas o ator, muitas vezes, o mostra falho a este respeito. Platão acredita que a personificação do ator de outro personagem fará com que os guardiões se afastem de seu próprio personagem. Platão, citado por Bernard Dukore (1974, p.7), pontifica que "os atores são imitadores das cópias imperfeitas de uma vida ideal; eles são de terceira mão e irreais e não podem nos ensinar nada de valor sobre a vida'“.

1 Embora globalmente muitas atrizes agora preferem se referir a si mesmas como atores, nós ainda empregamos o uso de atrizes para artistas femininas de tela ou palco neste estudo para equilibrar nossa ideia de papéis de gênero. Isso está em consonância com o argumento de definir os papéis de gênero no drama nigeriano, tal como foi discutido no Mabel IE Evwierhoma, a Mãe é Ouro: A Mater, a Matéria e as aborda- 
Por esta razão, Platão defende que os atores deveriam ser expulsos de sua república ideal. Ele ainda sustenta que os atores / atrizes têm uma má influência moral sobre aqueles que os ouvem e observam, pois logo aprenderão a admirá-los e a se moldar sobre as fraquezas e falhas de seus atos. Depois de Platão, vem um grande teórico da mesma era, um estudante de Platão. Este grande filósofo se chama Aristóteles. Na Poética, escrita em cerca de 335 a.c, Aristóteles, citado por Dukore, afirma que o drama é a imitação dos homens em ação, não os próprios homens, e esses homens são necessariamente bons ou ruins, dependendo da natureza do seu caráter, e sabendo que os homens diferem na sua natureza moral de acordo com o grau de sua bondade ou maldade, o caráter dramático deve sempre cair em uma dessas categorias (Dukore, 1974, p. 21).

Aristóteles afirma que o drama está preocupado com o retrato do universal. Portanto, o ator ou a atriz se preocupam em ensinar à sociedade sobre a vida, apresentando tal verdade nos palcos ou nas telas, o que irá percorrer um longo caminho para provocar uma mudança de coração e atitude através da catarse. Chegando ao período medieval, Tertuliano, como Platão, escreve contra o ator em seu trabalho "Sobre os espetáculos". Ele vê as atividades do ator como um pecado sério contra Deus e alega:

Vós, servos de Deus, prestes a aproximar-se de Deus, para que façais consagração solene de vós mesmos para Ele, buscam bem compreender a condição da fé, os motivos da verdade, as leis da disciplina cristã, que proíbem, entre outros pecados mundanos, o prazer dos espetáculos públicos [...] (Dukore, 1974, p. 36).

gens centradas nas mulheres no Drama e no Teatro da Nigéria (18 ${ }^{a}$ Conferência Inaugural) (Abuja: Universidade de Abuja Press, 2016).
Ele aconselhou que todo espetáculo é uma assembleia dos ímpios, que o drama pertence ao diabo e que os prazeres teatrais são formas de luxúria. Para ele, os cristãos não devem usar as mãos que levam a Deus em louvor e adoração para aplaudir os atores. Ele sustenta que os atores / atrizes em suas atividades atraem as pessoas para comportamentos imorais (Dukore, 1974, p. 85). Por outro lado, Giovanni Boccaccio escreve em favor do ator / atriz em sua crítica, "A Genealogia dos Deuses Cristãos" (cerca de 1365). Para ele, a poesia nos oferece muitos incentivos à virtude, e essa poesia procede do seio de Deus. A poesia é relevante para a sociedade porque estimula o sentimento de virtude em seus membros. Ele argumenta que os atores, através da poesia, veiculam a verdade em uma roupa justa e adequada de ficção com o único propósito de transmitir uma mensagem. Ele também observou que os personagens dramáticos e os atores / atrizes não são pior do que os personagens ou as pessoas nas escrituras sagradas (Dukore, 1974, p. 85).

$\mathrm{Na}$ Inglaterra, quando os puritanos assumiram o governo, condenaram o ator pelo que eles chamavam de "imoralidade do palco inglês". Um homem chamado Stephen Gosson, crítico do período renascentista, escreve fortemente contra o ator em seu trabalho, "Escola do Abuso" (1579). Ele afirma que a presença do teatro mostrou a decadência moral na Inglaterra, que o teatro proporcionou oportunidade para a imoralidade para aqueles que o assistem. Ele diz que "Romulus construiu o seu teatro como uma feira de prostitutas para prostitutas" (Dukore, 1974, p. 103-104). Além disso, ele coloca que o teatro é uma escola de abuso, o que significa que os atores são professores de abusos e atos imorais. $O$ teatro 
deste período foi até mesmo construído fora da cidade porque, de acordo com Gosson e com aqueles de sua escola de pensamento, o ator tem uma influência maligna que pode afetar a cidade. De fato, devido ao medo da prisão, os atores atuavam sob proteção de pessoas poderosas e usavam o brasão dessas pessoas para proteção. Os atores eram vistos como vagabundos (Dukore, 1974, p. 162). Do mesmo modo, Oscar Brocket afirma que o teatro veio da Inglaterra para os Estados Unidos da América (EUA) após o fim da guerra revolucionária (Brockett,1991, p. 364). Por conseguinte, em 1782, Thomas Wall, ex-membro da tropa, Douglas apareceu em Baltimore e no ano que se seguiu, ele juntou-se a Dennis Ryan para formar a American Company. Brocket (1991, p. 364) observou ainda que, no oeste dos EUA, o teatro de procissão começou em 1815, quando Samuel Drake levou uma companhia a Kentucky. ( Brockett,1991, p. 367).

No século XIX, embora atores e atrizes tenham recebido aplausos e tenham obtido sucesso financeiro, eles continuaram a ser considerados por muitos como um tanto indecorosos. No final do século, no entanto, a situação mudou a tal ponto que, em 1895, a rainha da Inglaterra, Victoria, deu o título de cavaleiro a Henry Irving, o primeiro ator a ser condecorado com esta honraria. Tal glorificação tornou-se quase comum nos anos seguintes, tanto na Europa como na América, com atores / atrizes recebendo considerável respeito. Na verdade, um dos presidentes mais aclamados da América, Ronald Reagan, era um ator.

$\mathrm{Na}$ África, a profissão de ator é vista como mal sucedida. Para as meninas, é considerada uma profissão para as rebeldes que querem se expor aos homens. É provável que, por essa razão, J.C. De Graft escreveu sua peça,
"Filhos e Filhas", retratando uma família de classe média, onde o pai, um rico empresário, quer que seus filhos sejam pessoas influentes na sociedade. Por esse motivo, ele escolhe e impõe cursos para os filhos. De acordo com James Ofosu, na peça, os médicos, contabilistas, engenheiros e advogados são os profissionais mais respeitados na sociedade e, por essa razão, ele proíbe seu último filho, Aron, e sua única filha, Mamman, a se inscreverem para cursos de pintura e dança na universidade, respectivamente. Descrevendo especificamente o caso nigeriano, Joel Adedeji (1981, p. 228) afirma que "quando o teatro itinerante ioruba emergiu do Egungun, os atores foram chamados de Alarinjo, significando um abuso que rotula os atores como rogues, vagabundos e mendigos". Os atores / atrizes eram geralmente considerados socialmente inferiores apesar dos seus esforços nos palcos / telas e fora de tais contextos performativos.

Corroborando o que precede, SonnyOti (1978, p. 126) afirma que "a sociedade nigeriana na avaliação do indivíduo na comunidade vê o ator / atriz como uma ovelha negra da família, porque ele ou ela é considerado um pobre assalariado". Ele vai mais longe para nos insinuar a reação da sociedade em relação ao ator e sua profissão, como ele diz, "a comunidade reage ao ator como faria com um" Osu "(excluído)" (Oti,1978, p. 126). Nessa mesma linha, rumores sobre atores e atrizes abundam na indústria cinematográfica nigeriana (Nollywood) - uma plataforma artística que emergiu em grande parte do Estado Nigeriano. Essas histórias giram principalmente em torno de delitos imaginários / atos ruins. Na maioria das revistas / jornais publicitários, lemos sobre atores e atrizes que são dependentes de substâncias químicas, maníacos sexuais e lésbicas 
ou gays - é uma ofensa criminal ser lésbica ou gay na Nigéria. FemiOsofisan (2001, p. 66) sustenta que a impressão negativa sobre os artistas de teatro também emana do mito da imoralidade. Ele opina que: "[...] o medo é que a profissão de teatro é uma instituição corrupta, um catalisador para uma vida de infidelidade e instabilidade conjugal [...]". No que diz respeito a muitas pessoas na sociedade, os artistas de teatro vivem uma vida muito precária.

Isso talvez explique porque Victor Dugga(2001, p. 6) argumenta que "o artista de teatro foi visto em alguns lugares como um patife, um palhaço, um indigente, um vagabundo e um desajustado social que tem pouco ou nada de bom para oferecer". De fato, os equívocos sobre a arte do ator levaram a alguns dos problemas que a profissão e os profissionais encontram no ambiente cultural e de entretenimento nigeriano. No entanto, um número considerável de pessoas, não se importando com as opiniões errôneas de outros sobre o ato do ator / atriz, ainda vê o ator ou atriz e seu ato como meio de comunicação. Brain Bates, citado por Beneditt Robert (1990, p. 1), afirma que:

Quase tudo o que os atores fazem pode ser identificado com coisas que fazemos de forma menos dramática na vida cotidiana. Mas, para expressar as verdades concentradas que são a vida do drama, e para projetar uma performance convincente diante de um grande público e o olho penetrante da câmera de cinema e televisão, o ator deve desenvolver poderes de autoconhecimento e de expressão muito além daqueles com os quais a maioria de nós é familiar.

A citação acima mostra que um ator ou atriz sempre faz um ato intencional. Embora o que ele / ela faça possa ser visto em atividades cotidianas, seu/ sua ação é proposital e cheia de sentimentos. Um ator ou atriz tem a obrigação de viver seu ou sua personagem interiormente e depois dar à sua experiência uma encarnação externa. Assim, um ator / atriz é como duas pessoas em uma. Ele / ela é um ator / atriz, bem como um personagem. Portanto, temos um ator - como - ator e um ator - como - personagem. H.D. Albright, William Halsted e Lee Mitchell (1968, p. 82) opinam que "de fato, o ator é convidado a ser dois artistas de uma vez: um intérprete e um instrumento de interpretação". Isso é, um ator é ao mesmo tempo artista e meio. Além disso, afirma-se que o ponto discutido, portanto, é que cada artista / ator / atriz de sucesso deve operar simultaneamente em ambos os níveis, mas que seu foco como ator / atriz deve permanecer em proporção adequada ao seu foco como personagem. (Ibidem, p. 83). É nesse contexto que este estudo examina a arte de atuar, atores e atrizes, e como sua habilidade pode ajudá-los a fazer uma distinção entre a vida dos palcos ou das telas e a vida cotidiana normal para garantir uma melhor apreciação da profissão teatral e seus profissionais na sociedade, particularmente em referência à Nigéria.

Atuação

Essencialmente, a atuação é a representação de um personagem geralmente ficcional no palco ou nos filmes. No seu mais alto nível de realização, a atuação envolve o emprego de técnicas e / ou uma identificação imaginativa com o personagem por parte do ator / atriz. Desta forma, o peso emocional total das situações nos palcos / telas pode ser comunicado ao público com a finalidade de educação, edificação espiritual ou diversão. Constantin Sta- 
nislavski (1952, p. 81) afirma que:

Um ator enquanto atua se volta para seus instrumentos criativos espirituais e físicos. Sua mente, vontade e sentimentos se combinam para mobilizar todos os seus elementos internos ... dessa fusão de elementos surge um estado interior importante ... o estado criativo interno. O hábito de estar diariamente no palco e no estado criativo certo é o que produz atores que são mestres de sua arte.

Além disso, Peter Brook, citado por Theodore W. Hatlen (1973, p. 243), opina que a atuação não deve apenas refletir a realidade, mas transcender o lugar comum da vida cotidiana, exagerando deliberadamente e distorcendo a realidade através de técnicas de atuação estilizadas. Ele afirma que:

A atuação é de muitas maneiras bastante única em suas dificuldades porque o artista tem que usar o material traiçoeiro, mutável e misterioso de si mesmo como seu meio. Ele é chamado para ser completamente envolvido ao mesmo tempo que distanciado, separado sem estar desapegado. Ele deve ser sincero, ele deve ser insincero, e ele deve praticar para ser sincero com sinceridade e como mentir com sinceridade [...].

\section{Ator / Atriz / Performer como uma construção}

Para entender o significado da palavra "construção", gostaríamos de conceituá-lo. Encarta (2008) a define como "construir ou montar algo, juntando partes separadas de uma maneira ordenada". A partir do exposto, pode-se ver claramente que a "construção" envolve a utilização de diferentes ferramentas e recursos, físicos ou mentais, para formar um elemento unificado. Assim como ocorre na atuação. No entanto, gostaríamos de afirmar que outra frase para 'ator como construtor' é 'ator como artista criativo'. Por isso, ambos são indistintamente usados para significar o mesmo no presente estudo.

$\mathrm{Na}$ atuação, um ator / atriz finge ser algo que ele ou ela não é, o que ele ou ela construiu. Para ser um bom ator / atriz, é preciso passar uma ideia de que um é o que não é. Ou seja, passando o que se construiu para os espectadores, desempenha-se um papel que na verdade o ator ou atriz não possui. Edwin Wilson (1988, p. 244) afirma que agir não é fingimento. Um ator não finge ser um Macbeth como um impostor que pretende ser o que ele não é; ao invés disso, ele cria (grifo nosso) uma aparência que se destina à percepção como ilusão. Criar um personagem crível é uma parte importante da atuação, onde os personagens se assemelham a seres humanos reconhecíveis. No entanto, uma abordagem realista tornou-se mais importante do que nunca no final do século XIX, quando o drama começou a descrever personagens e situações próximas da vida cotidiana (idem). Não só o espírito da personagem, mas também os detalhes tinham que se adequar a como as pessoas viam a vida ao seu redor. Isso colocou grandes exigências sobre atores e atrizes para evitar qualquer limite de falsidade ou superficialidade. Hubert Heffner (1959, p. 236) afirma que um ator deve construir em sua imaginação uma imagem do tipo de indivíduo que ele retrata e se identificar com esse indivíduo.

No entanto, o processo criativo é uma maneira de satisfazer essa ânsia ou busca de um ator ou atriz para criar um novo personagem dramático que não é facilmente encontrado ou alcançado. Essa ânsia e busca muitas vezes 
são observadas não só durante o processo criativo (caracterização), mas também no próprio produto criativo (um personagem dramático). Silvano Arieti (1976, p. 4) insiste que “... a criatividade humana usa o que já existe e está disponível e o muda de maneiras imprevisíveis". É necessário que o ator / atriz se esforce para transcender esses preconceitos e criar o personagem de modo diferente, transportando o público para uma compreensão do - e uma compaixão para com o - personagem. Originalmente, no entanto, estes não são atributos exclusivos de grandes homens ou mulheres, mas de todo ser humano. A criatividade não depende do talento herdado, do ambiente ou da educação, mas depende do ego ou do senso de si próprio. A criatividade, então, ocorre quando um ator ou atriz parte um pouco de si mesmo, modificando sua personalidade para criar um novo personagem dramático.

Além disso, para um ator ou atriz construir um personagem crível nos palcos ou telas, Hatlen (1972, p. 232) diz que ele ou ela “... deve servir uma função dupla, ele / ela cria e interpreta. Ele / ela não reproduz apenas uma cópia fiel da vida. Ele / ela seleciona, aumenta, expande [...]. Isso implica que mesmo que "o drama seja uma fatia de vida", um ator ou atriz deve tentar duplicar nos palcos / telas tudo o que ele não poderia duplicar na vida. Ele ou ela deve criar um personagem capaz de convencer seu público e transmitir sua mensagem intencional sem alteração. É dever de um ator / atriz olhar dentro de si mesmo e em torno de seu ambiente, a fim de descobrir os materiais / recursos que o capacitarão a criar um personagem com eficácia. A este respeito, Eva Miller (1982, p. 12) afirma: "eu acredito no trabalho exterior e, como ator, eu tendo a começar de como um personagem se parece, usando o que ele diz sobre si mesmo na peça. Talvez eu não seja como essa pessoa, mas tenho que chegar o mais perto possível dela".

Esta observação nos faz acreditar que, para um ator ou atriz construir um personagem dramático real, ele ou ela deve analisar a dramaturgia da peça ou o roteiro do filme. Ao fazer isso, o ator / atriz necessita descobrir a fisiologia e os temperamentos do personagem e começar a trabalhar em si mesmo para se parecer com o personagem pretendido. Louis Styan (1975, p. 14) afirma que Brecht e Genet exigiam que o ator atuasse livremente dentro e fora do personagem. Isso ilustra que um ator / atriz tem uma dupla vantagem de ser humano como seus personagens e, ao mesmo tempo, é capaz de personificar as criaturas de uma ficção irreal. Mas o que precede não pode ser possível, a menos que o ator / atriz construa o personagem que ele ou ela está representando habilmente. Estamos acostumados a ver atores ou atrizes personificando personagens da maneira mais realista possível, tentando convencer-nos da realidade viva das figuras que representam. Isso só é possível se o ator ou atriz faz o seu trabalho "criativo" efetivamente. Talvez, isso explique porque Styan (ibidem, p. 143) afirma ainda que "o trabalho do ator é, portanto, exclusivamente criativo". Em vista disso, pode-se dizer que não há ator ou atriz se não há criatividade na vida de um tal ator ou atriz. Em outras palavras, a vida de um ator ou atriz consiste no que ele ou ela pode criar.

Conflito entre a personalidade real e a personalidade construída de um ator / atriz

Ao longo dos anos, houve um conflito no 
comportamento dos atores ou atrizes entre o que eles ou elas já haviam construído e sua personalidade real. Muitos atores / atrizes foram influenciados imensamente pelo que eles representaram nos palcos ou nas telas. Por exemplo, um dos principais atores do popular New Masquerade, A Vida Diária de Chefe Zebrudaya (seu nome real é Chika Okpala) é dito ter sido extremamente afetado por seus papéis nos palcos e nas telas (Eni, 2014). Nós vemos desafios semelhantes nas vidas de NkemOwoh com a fama de "Osuofia em Londres", Hafix Oyetoro, com a fama de 'Saka', Funke Akindale com a fama de 'Jenifa', John Okafor, com a fama de Sr. Ibu, entre muitos outros no ambiente de atuação nigeriano. Neste momento, pode não estar fora de lugar examinarmos as várias maneiras de ver conflitos na vida de um ator ou uma atriz tanto nos palcos quanto nas telas e na vida real.

É triste afirmar que o comportamento de alguns atores ou atrizes fora dos palcos / telas é de cerca de $80 \%$ do que eles representaram (construíram). Muitas vezes, um ator / atriz se comporta de acordo com o que ele ou ela representou nos palcos / telas, o que faz com que muitas pessoas (incluindo entusiastas do cinema ou do teatro) acreditem que um ator ou atriz vive uma vida falsa. Robert Cohen (2007, p. 65) afirma que:

Alguns argumentaram que os atores devem viver seus personagens na vida real. A crítica de teatro francês Sainte Albine (1747) propôs que apenas os atores que realmente estivessem apaixonados pudessem desempenhar os amantes no palco efetivamente, a menos que pudessem desenvolver uma "insanidade feliz" que poderia persuadi-los de que eles estavam experimentando exatamente o que seus personagens pareciam experimentar; e pelos próximos dois séculos, os grandes atores foram pensados como promíscuos ou insanos.
O trecho acima demonstra que não começaram hoje os casos de atores ou atrizes que vivem suas vidas nos palcos ou telas em sua vida real. Muitos atores / atrizes / intérpretes em sua busca por viver de acordo com sua vida nas telas ou vida nos palcos fizeram uma série de erros que vão desde serem viciados em drogas a serem promíscuos ou gastadores - as vidas e carreiras de Marilyn Monroe, Michael Jackson, Bobbi Kristina Brown, Majek Fashek, Whitney Houston, entre outros, ilustram este ponto. Além disso, alguns atores / atrizes não são naturalmente ricos, mas devido ao fato de terem desempenhado muitos papéis como homens ou mulheres ricas, eles costumam se comportar ou viver como tal. Dafoe, citado por Cohen, diz que:

Eu acho que todos os personagens que eu representei são basicamente eu. Eu acredito que, sob esse conjunto certo de circunstâncias, somos todos capazes de qualquer coisa, e que a atuação permite que a parte mais profunda da sua natureza seja superada. O teatro, portanto, providenciou o palco não só para personagens e desenvolvimento dramatúrgico, mas também para incorporação e auto-expressão dos atores, e tem feito isso desde o início dos tempos (Cohen, 2007, p. 41).

No texto que precede, Dafoe parece propor que um ator ou atriz deve viver sua vida nos palcos ou telas e sua vida real como se fossem a mesma. Mas, quão plausível ou bom é isto? O que Dafoe está sugerindo é que se ele personificar um ladrão armado nos palcos ou nas telas, isso deveria ser o que ele está vivendo em sua vida real. Se acreditarmos que o drama é "fazer crer", não vemos nenhum motivo pelo qual um ator ou atriz profissional deve continuar vivendo sua vida nos palcos / telas na sua vida real. Talvez, esse tipo de pensamento tenha feito muitas pessoas perderem interesse 
pelos atores ou pela profissão de ator.

Assim, diríamos que toda a base da vida e do trabalho de um ator ou atriz consiste na impossibilidade de separar o "Eu" mundano do "Eu" dos palcos ou das telas. A máxima de Bernard Shaw, de acordo com Charles Mc Gaw, é de que "a única coisa que não é perdoável em um ator é ser o personagem ao invés de representá-lo" (Mc Gaw 2004, p.III). Um ator, segundo ele (idem), deveria desempenhar um papel e não ser esse papel. Ou seja, um ator ou atriz que não se importe com a forma como ele ou ela está representando qualquer personagem deve sair desse papel tão logo ele ou ela tenha terminado de representá-lo. Bowskill (1979, p. 1) concorda com esta posição, argumentando que "a autoconsciência é a pedra angular da arte e da arte da atuação". Portanto, para um ator ou atriz se sair bem ou levar uma vida profissional melhor lado a lado com suas experiências verdadeiramente vividas, ele ou ela deve ter auto-consciência, sabendo que ele ou ela está apenas atuando e não sendo a personagem.

\section{Conflito entre as Construções}

A atuação pode ser vista como a arte de (re) apresentar um personagem através de meios vocais e visuais nos palcos ou nas telas, de forma a convencer e agitar ou transportar o (s) público (s) a certas realidades (Omoera, 2005, p. 41). Parece que a maioria dos atores e atrizes nigerianos não veem a atuação dessa forma; eles tendem a ver a atuação como uma maneira de fazer as coisas como de costume. Ao atuar em um determinado papel, o ator ou a atriz procuram uma maneira de tornar o personagem que ele ou ela está representando com sinceridade na interpretação vocal, maneirismo e termos psicológicos. A tendência comum da maioria dos atores / atrizes (até mesmo diretores) na Nigéria de se dedicar de tal forma a um personagem que eles não conseguem desempenhar outros papéis efetivamente é imprudente e antiética. A maioria dos atores ou atrizes tendem a ter problemas para interpretar um determinado personagem simplesmente porque o que eles construíram está em conflito com o que estão construindo. Por exemplo, muitos atores / atrizes, tendo desempenhado muitos papéis como homens ou mulheres ricas, acham difícil desempenhar o papel de um homem pobre. Mesmo quando alguns o fazem, você estará vendo o "fantasma" de seu papel passado em sua construção atual - algumas atividades profissionais de Jide Kosoko, um ator nigeriano famoso, ilustra em grande parte o fato aqui colocado. É o que denominamos, no contexto da nossa discussão, de o conflito das construções. Dorothy Birch (1952, p. 1) afirma que:

Atuar é representar um personagem para que você se comporte como ele o faria, mas isso é importante - você deve representar de acordo com as técnicas teatrais, de modo que, embora você não se comporte exatamente como na vida real, você pareça fazê-lo [...]. Para se adequar ao padrão do palco projetado para dar a ilusão do real. Para atender às condições do palco, você deve modificar sua aparência $[\ldots]$.

Mas o caso da atuação nigeriana contemporânea é como o trecho acima descrito? A resposta é não! A maioria dos chamados atores/ atrizes profissionais que escolhem sempre o mesmo tipo de papel a ponto de eles tenderem a viver sua vida das telas ou palcos no seu dia-a-dia - o Chefe Zebrudaya, Ime Bishop Umoh (Okon Calabar) simbolizam esta tendên- 
cia entre atores / atrizes nigerianos. É provavelmente por isso que eles acham difícil aderir ao conselho de Birch (1952, p. 1) quando ela observou que "para se adequar à condição do palco, você deve modificar sua aparência". A maioria dos atores / atrizes que tomaram suas construções como modo de vida acham impossível se modificar para se adequar ao seu novo papel, o que leva a uma má atuação. No entanto, a atuação envolve a pessoa humana na sua totalidade; o ator ou atriz usa seu corpo, mente, voz e até mesmo sua vontade de criar o que o público descobre ser um personagem que vive dentro da moldura de uma peça de teatro ou de um filme. Quando alguém constrói um personagem, sua criação pode ter quatro (4) formas: traços físicos; traços sociais; traços psicológicos; e, traços morais. Pode ser importante examinar esses traços, mesmo que brevemente:

1. Traços físicos: envolve a análise de um personagem em termos de atributos fisionômicos. A este respeito, descobre-se como o personagem se parece; ele / ela é gordo, magro ou forte. Alguns desses traços podem ser vistos na direção onde o roteirista / dramaturgo descreve o personagem na dramaturgia ou roteiro, ou através de outros personagens. Por exemplo, Arthur Miller (1985, p. 2) em "Deathof a Salesman" diz sobre Willy Loman: "Ele tem mais ou menos sessenta anos de idade; vestiu-se em silêncio ... o cansaço é aparente".

2. Traços sociais: se relaciona com o ambiente e com as pessoas que cercam o personagem no roteiro ou na dramaturgia. $O$ caráter educacional e social do personagem, o status e o tipo de trabalho que ele faz são os traços sociais que o roteirista / dramaturgo fornece no texto. Beneditt (1990, p. 98) afirma que:
Os traços sociais mais importantes são o relacionamento geral e específico que seu personagem tem com os outros personagens da peça ... os personagens dramáticos podem ser entendidos apenas em relação aos outros personagens em seu mundo.

Portanto, para que um ator / atriz compreenda seu papel, ele ou ela deve atentar para os traços sociais do personagem. Ubong $\mathrm{Nda}$ (2013, p. 48), embora em um contexto ligeiramente diferente, afirma que "os traços sociais envolvem um artista criando suas linhas e ações, de acordo com sua compreensão do papel atribuído em uma produção teatral”.

3. Traços psicológicos: este é um nível muito importante de caracterização porque justifica e motiva todos os outros traços. Qualquer ator ou atriz que não descubra os traços psicológicos do personagem que ele ou ela deve representar nunca poderá interpretar esse personagem de forma eficaz. Os traços psicológicos ajudam a tornar as ações desse personagem críveis.

4. Traços de moralidade: se referem aos valores do personagem ou do ator / atriz. São resultados dos pensamentos do personagem e dos sentimentos conscientemente ou inconscientemente expressados.

Essencialmente, esses diferentes níveis de caracterização que nós analisamos contribuem para as ações dramáticas que são realizadas em termos de objetivo revelado pelo personagem e objetivos alcançados. Cada personagem responde a uma determinada ação de acordo com as orientações físicas, sociais, psicológicas e morais de sua personalidade. Mas muitos atores / atrizes da Nigéria realizam meticulosamente esses processos de caracterização? A resposta é não! Porque, se o fizessem, não haveria essas questões de 
conflito entre construções em muitas das produções nos palcos e telas da Nigéria, como observamos historicamente. Beneditt (1990, p. 21), teoricamente, enfatiza o problema da seguinte maneira: "talvez possamos enfrentar situações em que dois ou mais dos nossos 'eus' entrem em conflito uns com os outros". Deste modo, vemos que Robert acredita que as construções tendem a entrar em conflito entre si e é responsabilidade do ator ou da atriz proteger-se conscientemente contra tais conflitos.

\section{Separando a Identidade Real do Ator / Atriz de sua Construção}

Aqui, propomos algumas estratégias que os atores / atrizes da Nigéria poderiam usar para separar suas identidades reais de suas construções. Isto é, em vista da observação que fizemos anteriormente de que muitos dos personagens, que muitos atores e atrizes nigerianos construíram, estão em conflito com suas identidades reais. Deve-se notar também que, em vários casos, algumas das construções do ator ou atriz têm sido conflituosas ou entraram em conflito entre si. Assim, merecem ser analisadas estratégias que esperançosamente ajudem a colocar questões em melhor perspectiva para o ator / atriz nigeriano.

Além disso, a maioria das autoridades nigerianas na profissão das artes teatrais, especialmente na área de atuação, tendem a estar mais preocupadas com as formas através das quais se poderia ser um bom ator ou atriz. A maioria deles não percebeu ou parece não ter percebido que atores ou atrizes são seres humanos. Todos visam propor teorias de atuação, mas nenhuma delas visualizou essa "ferramenta" (ator / atriz) como um ser que precisa despir- -se de seus papéis depois de representá-los. Uma observação cuidadosa indica que muitos desses teóricos do realismo e da atuação realista não pensam sobre as consequências da atuação na vida de um ator / atriz.

Observamos que a maioria dos atores e atrizes foram afetados seriamente pelos papéis que haviam desempenhado. Alguns são agora dependentes químicos, enquanto outros são prostitutas e mulherengos por causa dos papéis que representaram alguma vez nos palcos ou telas. Essas pessoas podem ter lido sobre a definição de drama de Aristóteles como "uma imitação de ação" (Duroke, 1974, p. 36), como observado anteriormente. No entanto, os atores / atrizes devem ver o drama como um ato deliberado e devem segui-lo dessa maneira. Nesse sentido, Emeka Nwabueze (2005, p. 9) afirma que:

O drama envolve imitação, representação e um interesse deliberado em figurinos, modulação de voz, gestos e movimento em ritmo com as idiossincrasias do personagem imitado. Não é realidade, mas uma ilusão disso.

Mas aqueles que não vêem o drama como uma ilusão de realidade, o vêem como realidade. Eles também não o vêem como uma imitação ou representação, mas como uma forma de vida. Domba Asomba (2007, p. 7) afirma que "[...] o teatro em sua natureza é uma existência ilusionista, temporal e dependente". Isso significa que o teatro é limitado pelo tempo e dura enquanto as ações persistirem. Tendo isto em vista, começamos a nos perguntar por que muitos atores / atrizes nigerianos que participam de uma atividade que é temporal (ou seja, atuando nos palcos ou nas telas) carregam seus papéis permanentemente. Aqui, queremos olhar para os atores e atrizes como seres que só se tornam atores / atrizes 
quando começam a representar e param de atuar assim que a peça termina. No entanto, há casos em que um ator divorcia sua esposa, e se casa com uma atriz que representou com ele em uma cena de amor e vice-versa. Tais atores não seguem os caminhos prescritivos de Asomba, que disseram que o drama é um ato temporal ou Nwabueze, que disse que o drama é uma arte intencional, que não é ilusão real, mas deliberada.

$\mathrm{Na}$ atuação, um ator / atriz finge ser algo que ele ou ela não é. Ele ou ela está desempenhando um papel, o que, claro, ele ou ela não possui. Styan (1975, p. 141) opina que "estamos acostumados a ver atores personificando personagens da maneira mais realista possível, tentando o máximo de sua inclinação para nos convencer da realidade viva da figura que eles representam". Mas a citação acima não é motivo suficiente para que um ator / atriz tente replicar o mesmo na vida real. Tendo observado que o que fazemos (isto é, não separando a identidade real da construção como ator ou atriz) nos afeta de forma mais negativa do que positivamente, propomos as seguintes estratégias para remediar a situação.

1. Auto descoberta; 2. Equilíbrio / Consciência Psicológica; 3. Afastamento psicológico/ distanciamento.

\section{Auto descoberta}

Este é o primeiro passo que um ator ou atriz deve tomar para se separar de sua construção. O primeiro dever de um ator ou atriz é descobrir que ele ou ela é um ser humano como qualquer outra pessoa. Antes de se tornar um ator ou atriz, ele ou ela viveu entre outras pessoas, inclusive familiares próximos. Atores / atrizes devem descobrir que ser ator / atriz não é estar procurando por um modelo a seguir, mas sim usar-se como um "instrumento" para transmitir uma mensagem teatral ou fílmica ao público. Um ator / atriz deve descobrir em seu subconsciente que ele ou ela não é um ator / atriz desde o nascimento, mas aprendeu ou escolheu a atuação como uma forma de viver. Ao fazê-lo, ele ou ela se torna mais consciente de que criou um personagem. $\mathrm{Na}$ auto descoberta, um ator / atriz percebe que há apenas um 'Eu' em sua vida, que é a pessoa real e que qualquer coisa que ele ou ela cria, são seus 'eus'. Auto descoberta é o primeiro passo na vida de qualquer ator ou atriz que deseje efetivamente separar sua identidade real de suas construções.

\section{-2. Equilíbrio / Consciência Psicológica}

Deve ser afirmado aqui que tudo o que acontece com um ator ou atriz após a cena é puramente psicológico. Um ator deve equilibrar sua psique, que ele ou ela é apenas uma pessoa comum tentando construir um personagem crível nos palcos ou nas telas. Ao construir um personagem, um ator ou atriz deve ter em seu subconsciente que ele ou ela é agora "uma pessoa" vivendo em uma pessoa. Styan (1975, p. 141) afirma que o ator ou atriz tem a dupla vantagem de ser humano, como seus espectadores, parecendo-se com eles, capazes de representar e demonstrar seus sentimentos e, ao mesmo tempo, capazes de representar a criatura de uma ficção irreal dando um tipo de vida às figuras da fantasia pura.

Na verdade, Styan (1975, p. 141) acredita que um ator / atriz tem o poder de olhar para si mesmo enquanto age e, ao fazê-lo, ele / ela 
está equilibrando-se. Um ator / atriz deveria, a todo momento, tentar saber que o que ele / ela está representando não é seu verdadeiro eu, mas uma construção. Para ele ou ela efetivamente fazer isso, ele ou ela deve equilibrar a psique dos seus dois indivíduos (sua construção e sua identidade real). Atores / atrizes que não conseguem fazer isso acabam se tornando atores e atrizes de repertório, estereotipados, porque eles facilmente tomam consolo em seus papéis passados. Para que qualquer ator / atriz separe sua identidade real de sua construção, ele / ela deve ser alguém que saiba como equilibrar a diferença entre o seu eu real e a sua construção. Isso ajudará ele ou ela a se tornar consciente do que ele ou ela está fazendo, assim, lembrando-lhe que ele / ela não é o que ele ou ela está criando, mas um ser diferente. Qualquer um que queira ser um bom ator ou atriz deve aprender a se equilibrar psicologicamente para se tornar consciente de sua identidade real.

\section{Distanciamento psicológico}

Depois de equilibrar sua identidade real com a construção, um bom ator ou atriz deve tentar distanciar um do outro. Muitos atores / atrizes da Nigéria têm intencionalmente visado identificar-se com os papéis que eles representaram no palco ou na tela. Hubert Heffner (1959, p. 236) afirma que "um ator deve construir em sua imaginação uma imagem do tipo de indivíduo que ele está retratando e se identificar com esse indivíduo". Não importa como ele ou ela tenta se identificar com o personagem, ele ou ela deveria distanciar-se psicologicamente do papel sabendo muito bem que ele ou ela é apenas um artista criativo - uma embarca- ção para outra criação. A maioria dos atores e atrizes enfrentam problemas quando alguns fãs os chamam pelo seu nome de palco ou de tela. Isso faz com que a maioria dos artistas nigerianos, especialmente os comediantes, comecem a se comportar como o personagem que haviam representado para atender às expectativas de seus fãs / amigos - nós vemos isso acontecer incessantemente com comediantes nigerianos populares, incluindo Francis Agordie, também conhecido como "Eu" Go Die ', Imeh Bispo Umoh da famosa' Okon Calabar ', entre outros. Qualquer ator / atriz que saiba como se distanciar de seu papel não fará isso porque ele ou ela sabe que o drama, seja no palco ou na tela, existe no tempo e no espaço e esse personagem vive e morre com o drama - Olu Jacobs, Zack Orji, GenevieveNnaji, Ramsey Nouah, Richard Mofe-Damijo, Joke Silva, entre outros, são exemplos brilhantes na cena nigeriana que foram adiante para ocupar posições proeminentes fora de suas carreiras de atuação.

O afastamento psicológico / "distanciamento" ajuda um ator / atriz a não permanecer no seu personagem depois de representar esse personagem no palco ou na tela. Tomemos como exemplo um dos nossos amigos do sexo masculino que desempenhou o papel de 'Akpan' em uma peça e, depois disso, ele começou a falar e a andar como Akpan para fazer as pessoas rirem, ele continuou a exibir os maneirismos de Akpan porque Akpan é um personagem cômico. Isso levou mais de $80 \%$ de sua identidade real e as pessoas agora o vêem como uma pessoa que não é séria e o pior, ele não pode desempenhar um papel sério agora, exceto papéis cômicos como Akpan - ele se tornou um personagem de repertório. Se ele tentasse distanciar-se do papel psico- 
logicamente, isso o ajudaria a evitar tornar-se estereotipado. O 'distanciamento' psicológico ajuda os atores ou atrizes enquanto criam ou personificam um personagem para saber quem eles ainda são.

\section{Conclusão}

Acredita-se amplamente que a atuação é a profissão mais desconcertante do mundo. Entendemos que a atuar é imitar uma ação e todos nós temos uma história de imitação. No entanto, atuar é uma arte e os atores / atrizes são pessoas privilegiadas que conseguem viver a vida de alguns dos personagens mais conhecidos do mundo, nos trazendo de volta a história. Atores / atrizes representam seres humanos de todos os setores da vida e para fazer isso efetivamente, eles devem saber algo sobre a humanidade em geral. Atores / atrizes foram vistos ao longo dos tempos como artistas e eles também se vêem do mesmo jeito. Embora essa percepção seja boa, eles (particularmente atores e atrizes da Nigéria) devem aprender ou ser ensinados a separarem-se conscientemente do que eles constroem nos palcos ou nas telas. Como Joan Snyder (1972, p. 2) afirma “... quando você retrata um personagem no palco, você geralmente fica bastante diferente de você mesmo". Atores e atrizes da Nigéria devem aprender e reaprender que os principais requisitos dos atores ou atrizes são o senso comum, potências aguçadas de observação e percepção, tolerância e compreensão com os seres humanos e um sólido conhecimento geral da sociedade; eles devem discernir minuciosamente que são "dois em um" (a verdadeira identidade e a construção). Uma profissão é uma profissão; a única dife- rença é o quão bem se conhece a profissão e quão boa é seu papel na profissão e o que se pode distinguir do que se construiu e de quem se é. Para qualquer ator ou atriz afirmar que ele ou ela é um profissional, ele ou ela deve aprender a matar os tipos estereotipados de atuação que possuem. Ele ou ela não deve ser um ator estereotipado, isto é, um ator que somente sabe desempenhar um papel particular ou similar sempre.

Os diretores e produtores nigerianos, tanto de palco como de tela, também devem ajudar atores / atrizes, variando seus papéis, nem sempre dando a eles determinados papéis similares. A síndrome generalizada de chamar um ator / atriz e lançá-lo para desempenhar um papel particular sempre torna esse ator ou atriz um ator / atriz de repertório. Além de não ser criativo, essa tendência não é saudável para o desenvolvimento da profissão de atuação na Nigéria. Além disso, faz com que o "ator" ou "atriz" em questão comece a copiar sua vida das telas e dos palcos para sua vida real - as vidas de Jim lyke, o "menino ruim de Nollywood" e Tonto Dike, A "garota malvada de Nollywood" são exemplos indiscutivelmente desconcertantes a este respeito. Afinal, atores ou atrizes são seres humanos, podem ser facilmente afetados pelo modo que agem, vêem ou ouvem. Na medida em que estamos dizendo aos atores ou atrizes para entrar em seu papel, também devemos pedir-lhes para aprender a sair de seu papel com a finalidade de terem uma personalidade saudável. É neste sentido que postulamos as três (3) etapas da autodescoberta, equilíbrio psicológico e distanciamento psicológico para ajudar os atores e atrizes em formação na Nigéria a separar suas identidades reais de suas construções. Quando um ator ou uma atriz se descobre e 
equilibra sua identidade real psicologicamente, além de se distanciar de sua construção, temos atores ou atrizes mais saudáveis fora do palco ou fora da tela. Atores / atrizes são indivíduos reais, não pessoas falsas e devem viver como pessoas reais.

\section{Referências}

Adedeji, Joel A. "Alarinjo, the Traditional Yoruba Travelling Theatre." Drama and Theatre in Nigeria: A Critical Source Book, edited YemiOgunbiyi. Lagos: Nigeria Magazine, 1981.

Albright, H.D., Halsted William P and Mitchell, Lee. Principles of Theatre Art (second edition). Boston: Houghton Mifflin Company, 1968.

Arieti, Silvano. Creativity: The Magic Synthesis. New York: Basic Books Publishers Inc., 1976.

Asomba, Domba. Scene Design Art and Craft. Ibadan: Caltop Publication Ltd., 2000.

Birch, Dorothy. Training for the Stage: The Technique of Acting. London: Sir Isaac Pitman and Sons Ltd., 1952.

Bowskill, Derek. Acting and Stagecraft made Simple. London: W.H. Allen and Company, Ltd., 1979.

Brockett, Oscar G. History of the Theatre (6thed.). Boston: Allyn and Bacon, 1991.

Cohen, Robert. Acting One (fourth edition). New York: McGraw Hill, 2007.

Dugga, Victor S. "Rethinking Training Imperative in Nigerian University Theatres." Nigerian Theatre Journal: A Journal of the Society of Nigeria Theatre Artists 9, no. 1 (2006): 5-15.

Dukore, Bernard F. Dramatic Theory and Criticism: Greeks to Grotowski. New York: Holt, Rinehart and Winston, Inc., 1974.
De Graft, J.C. Sons and Daughters. Oxford: Oxford University Press, 1969.

Encarta. "Construct." Microsoft $₫$ Encarta $₫$ 2009 [DVD]. Redmond, WA: Microsoft Corporation, 2008.

Evwierhoma, Mabel I. E. Mother is Gold: The Mater, the Matter and Women-Centred Approaches in Nigerian Drama and Theatre. (18th Inaugural Lecture). Abuja: University of Abuja Press, 2016.

Heffner, Hubert C. Modern Theatre Practice: $A$ Handbook of Play Production (fourth edition). New York: Appleton-Century Crofts Inc., 1959.

Hatlen, Theodore W. Orientation to the Theatre (second edition). New York: Meredith Corporation, 1972.

Kurt, Daw. Acting Thought into Acting. Portsmouth: Heinemann Inc., 1997.

McGaw, Charles C. Acting is Believing (8th edition). New York: Wadsworth, 2004.

Miller, Arthur. Death of a Salesman. London: Heinemann Educational Books Ltd., 1985.

Miller, Eva. Masters of the State. New York: Grove Weidenfield, 1989.

Nda, Ubong "Improvisation in the Theatre for Development Process." Ganga: Journal of Language and Literary Studies, 5 (2013):4862.

Nwabueze, Emeka P. In the Spirit of Thespis: The Theatre Arts and National Integration. (An Inaugural Lecture). Nsukka: University of Nigeria, 2005.

Omoera, Osakue S. "Actors/Actresses and their Responsibilities in Society." A Paper Presented in a Workshop by the Benin Chapter of the Actors Guild of Nigeria (AGN) at Broderick's Inn, Benin City, March12, 2005.

Osofisan, Femi. Insidious Treasons: Drama 
in a Postcolonial State. Ibadan: Oponlfa Publishers, 2001.

Oti, Sonny. "In Search of Nigerian Actor." Nigeria Magazine (1978): 126-127.

Robert, Beneditt. The Actor at Work (fifth edition). New Jersey: Prentice Hall Inc., 1990.

Runcan, Miruna. "Strategies for the Embodiment and Disembodiment of Spectatorship: Don't Cry Baby and Hotel by Eugen Jebeleanu."Studia Ubb Dramatica, LX, no.2 (2015):926.

."The Body of the Empathic Spectator." Echinox Journal 29 no.2 (2015): 29-52.

Stanislavski, Constantin. An Actor Prepares. Trans. Elizabeth Reynolds Hap Good. New York: Theatre Arts Books Inc., 1952.

Snyder, Joan. The Dynamics of Acting. Illinois: National Textbook Company, 1972.

Styan, Louis J. Drama, Stage and Audience. London: Cambridge University Press, 1975.

Uche-Chinemere, Nwaozuzu. "From Stage to Living: A Critical Reflection on the Status of the Modern Nigerian Actor." A Paper Presented at the African Circle of Artists Conference, Enugu, 2002. "Between Talent and Scholarship: A Critical Review of the Art of the Actor in Contemporary Nigeria." A Lecture Delivered at Alliance Frances, Enugu, April 5th 2007.

Wilson, Edwin. The Theatre Experience (fourth edition). New York: McGraw Hill Book Company, 1988. 